\title{
PREVALENCE AND FACTORS AFFECTING THE PARASITIC INFECTIONS IN CALVES AT SELECTED AREAS OF BANGLADESH
}

\author{
M. R. Karim ${ }^{*}$, S. M. M. R. Sumon', S. H. Soad', S. H. M. F. Siddiki ${ }^{1}$ \\ A. R. Dey ${ }^{3}$ and M. A. Ehsan ${ }^{2}$
}

\begin{abstract}
Gastrointestinal parasitic infections are considered as one of the major impediments in profitable livestock farming in subtropical and tropical countries. The present study was carried out to investigate the prevalence of gastrointestinal (GI) parasites and to determine the effects of different factors in the occurrences of GI parasitic infections in calves. A cross-sectional study, including 413 fecal samples from calves, was conducted in Pabna, Sirajgonj and Gazipur districts of Bangladesh. The samples were examined using standard coprological techniques like sedimentation and floatation techniques, and lugol's iodine and modified Ziehl-Neelson staining. The overall prevalence of gastrointestinal parasitism was $45.3 \%$ and commonly identified parasites were Toxocara spp. (20.3\%), Strongyloides spp. (3.9\%), Fasciola sp. (1.0\%), Moniezia spp. (1.5\%), Giardia sp. (10.4\%) and Cryptosporidium spp. (7.0\%). Among the factors, the age, sex and health status had significant effects on the GI parasitic infections in calves. Therefore, special care such as routine fecal examination for parasitism and proper deworming program should be taken to maintain good health and husbandry of calves for profitable livestock production.
\end{abstract}

Keywords: Gastrointestinal parasites, prevalence, calves, coprological techniques.

\section{Introduction}

Gastrointestinal (GI) parasitism is a disease caused by different genera of parasites that inhabit the digestive tract of animals, causing inappetence, anemia, diarrhea, poor growth, and economic losses in the herds. Basically, GI parasitism in livestock is caused by helminths and protozoa (Pinilla León et al., 2019). These infections are rarely associated with high mortality and estimated that about $10 \%$ animals die annually due to parasitic diseases in the world (Chavhan et al., 2008). However, their effects are usually characterized by reduced livestock productivity as indicated by a slower growth rate, low milk production, low body condition score (BCS) as well as additional therapeutic cost (Charlier et al., 2015). The productivity losses through reduced feed intake and decreased efficiency in feed utilization due to subclinical or chronic infections are also hindering profitable livestock industry (Akanda et al., 2014). In addition, these infections enhance susceptibility to secondary infections and

\footnotetext{
${ }^{1}$ Department of Medicine, Faculty of Veterinary Medicine and Animal Science, Bangabandhu Sheikh Mujibur Rahman Agricultural University, Gazipur 1706, ${ }^{2}$ Department of Medicine, Faculty of Veterinary Science, Bangladesh Agricultural University, Mymensingh 2202, ${ }^{3}$ Department of Parasitology, Faculty of Veterinary Science, Bangladesh Agricultural University, Mymensingh 2202, Bangladesh.

*Corresponding author: vet_robiul@bsmrau.edu.bd
} 
losses resulting from condemnation of carcasses and organs (Hendawy, 2018; Gunathilaka et al., 2018).

One of the major constraints in livestock production is parasitic infection (Jabber and Green, 1983). The prevalence of parasitic infection depends on ecology, geographical and climatic condition prevailing in Bangladesh (Hossain et al., 2004). The farmers usually rear their cattle under traditional husbandry practices. Nutritional status of the animals in general is not satisfactory as they are over-worked but under-fed or halffed, which makes the animal susceptible to diseases including different parasitic diseases. About $50 \%$ calves until 1-year of age die due to GI parasitism (Sardar et al., 2006). Rahman and Ahmed (1991) reported that calves gained body weight by $400 \mathrm{gm} /$ day when treated for parasitic diseases compared to $200 \mathrm{gm} /$ day in non-treated calves. It was also reported that anthelmintic treated calves reached to sexual maturity in 24 months compared to 3640 months by non-treated calves. Afazuddin (1985) estimated an annual loss of 0.1 million Bangladesh Taka due to parasitic diseases in Military Farm, Savar, Dhaka. Unfortunately, in Bangladesh the parasitic diseases are neglected or overlooked sometimes since the infected animals show little or no clinical signs (Alim et al., 2012).

In this study, we selected three districts namely, Pabna, Sirajgonj and Gazipur. The geo-climatic conditions of these three districts and the water logging and low lying areas of Pabna and Sirajgonj districts are expected to favors the growth, development and survival of various parasites or their hosts. Besides, there are several factors, such as breed, age, sex, nutritional and immune status which may influence the occurrences of GI parasitic infections. Although, previous studies in some selected areas of Bangladesh revealed wide prevalence of GI parasitism in livestock (Paul et al., 2016; Ahmed et al., 2015; Islam et al., 2014), no precise report on the infections is available in calves of these areas. Considering this, the present research work was undertaken to determine the prevalence of GI parasitic infections of calves in Pabna, Sirajgonj and Gazipur districts and to evaluate the effect of geographic location, breed, age, sex, nutritional status and fecal consistency on occurrence of GI parasitism.

\section{Materials and Methods}

\section{Study area}

The study was conducted in different locations of Sirajgonj, Pabna and Gazipur districts. The milk pocket areas of Sirajgonj and Pabna were chosen, because the farmers over there are mostly dependent on dairy farming and parasitic infection is more common in these areas. On the other hand, the industrial zone Gazipur was selected to compare the prevalence and diversity of GI parasitic infections with that found in another two districts. Among the 24 Upazilas of these three districts, six Upazilas were selected for this study, such as Sadar and Santhia Upazilas of Pabna district; Sadar, Ullapara and Shahjadpur Upazilas of Sirajgonj district; and Sadar Upazila of Gazipur district (Fig. 1).

\section{Study design and data collection}

A cross-sectional study was conducted in randomly selected dairy farms of study areas during the period from January 2018 to June 2018. The minimum sample size 


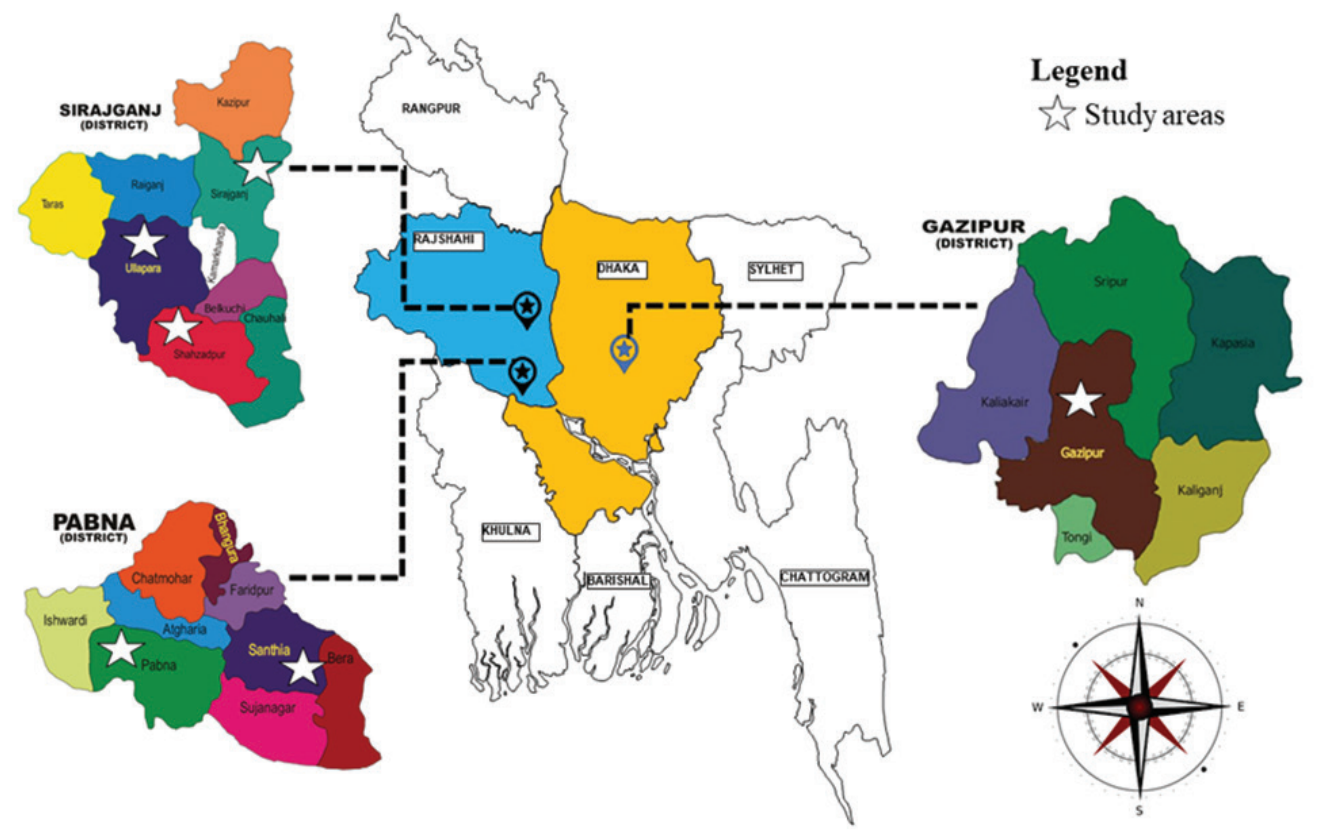

Fig. 1. Sampling locations of Pabna, Sirajgonj and Gazipur districts. The three districts have 24 Upazilas, of which this study included Sadar and Santhia Upazilas of Pabna; Sadar, Ullapara and Shahjadpur Upazilas of Sirajgonj; and Sadar Upazila of Gazipur.

$(\mathrm{n}=368.64)$ was calculated using the formula, $\mathrm{n}=\mathrm{Z}^{2} \mathrm{P}(1-\mathrm{P}) / \mathrm{d}^{2}$ based on a prevalence of $60 \%$ with desired precision of $5 \%$ at $95 \%$ confidence level (Thrusfield, 2007). A total of 413 calves were selected randomly for the collection of fecal samples ageing up to 8 months. During fecal sample collection, a pretested questionnaire was used to record the age, sex, health condition, breed, and level of consistency of fecal materials of calves. The calves were divided into three age groups viz. $\leq 3$ months, $>3$ to $\leq 6$ months and $>6$ to $\leq$ 8 months; different sex viz. male and female; different health status group viz. poor and normal; different breeds viz. Non-descriptive indigenous and crossbred. The ages of the calves were determined by interviewing the farmers or by examining the teeth. The health status of the calves was determined by visual observation. Well fleshed calves having no bony prominence and glistening hair coat was considered as calves with normal health. Calves with externally visible ribs and other bony prominence and rough hair coat were considered as poor health conditioned (Pinilla et al., 2018).

\section{Fecal sample collection and preservation}

Single fresh fecal sample from each consenting calf was collected in labeled and sterile stool containers containing SAAF solution (Sodium Acetic Acid Formalin). The fecal samples was taken either directly from the rectum of the animals or from the ground immediately after defecation using disposable gloves. Before collection, the animals were restrained properly and all possible hygienic measures including wearing apron, hand gloves and gumboot were taken to avoid contamination. 
About 20-25 gram of feces was collected from each calf and transported to the laboratory in ice box, and examined as early as possible.

\section{Examination of fecal samples}

The fecal samples were analyzed using standard parasitological screening techniques namely, sedimentation followed by floatation technique to detect the eggs, cysts and oocysts of parasites (Taylor et al., 2016). For identification of Giardia cysts and Cryptosporidium oocysts, lugol's iodine and modified Ziehl-Neelson staining were performed, respectively. The eggs, cysts and oocysts of parasites were identified from their morphological characters, using a light optical microscope with a magnification of $10 \mathrm{x}$ and $40 \mathrm{x}$.

\section{Simple Sedimentation Technique}

About 10 grams of faces and $100 \mathrm{ml}$ of saline solution were taken in a glass cylinder. The mixture was thoroughly stirred to make a uniform suspension of the fecal particles. The suspension was then allowed to pass through a sieve (30-50 meshes to the inch) into another glass cylinder and then allowed to stand for half an hour. The supernatant fluid was carefully poured off and a small amount of sediment was taken out with the help of a medicinal dropper and was placed on a glass slide. A coverslip was placed on it and care was taken to avoid bubble formation between the glass slide and the coverslip. The slide was then placed under a compound microscope and examined with low power objective 10x.

\section{Flotation technique}

Flotation procedure was performed using Sheather's Sucrose solution. The fecal pellet was resuspended in $10 \mathrm{ml}$ of Sheather's solution (specific gravity $1.27 \mathrm{~g} / \mathrm{ml}$ ) and mixed thoroughly. The mixture was increased up to the brim of the centrifuge tube and centrifuged for 10 minutes at $4000 \mathrm{rpm}$. The downward force created by the centrifugal spinning enhanced the buoyancy of the eggs in the viscous solution and drove them to the surface meniscus where they were concentrated and resulted in greater parasite recovery. Examination of a few drops of the fluid from the topmost layer revealed the eggs and oocysts/cysts (Dryden et al., 2005).

\section{Lugol's iodine staining}

Direct smear from the sediment of each concentrated fecal sample was prepared on a clean glass slide, diluted with a drop of Lugol's iodine, covered with coverslip and finally examined under light microscope at 40X magnification to observe the Giardia cysts (Hendrix, 2002).

\section{Modified Ziehl-Neelson staining}

Thin smears were prepared from sediments of concentrated fecal samples and airdried. The smears were fixed with absolute methanol for 5 minutes, air dried and stained with carbol-fuchsin $(0.34 \%$ fuchsin and $4 \%$ $\mathrm{w} / \mathrm{v}$ phenol) for 30 minutes. Smears were washed with tap water and decolorized with $1 \%$ acid-alcohol (1 $\mathrm{ml}$ hydrocloric acid and $99 \mathrm{ml}$ of $96 \%$ ethanol) for 2 minutes; washed with tap water and counterstained with $1 \%$ methylene blue for another 2 minutes, rinsed again in tap water and air-dried. The stained smears were examined by microscope using oil immersion objective to screen oocysts of Cryptosporidium (Tahvildar-Biderouni and Salehi, 2014). 


\section{Statistical analysis}

The data generated from the questionnaire and parasite identification were recorded in the Statistical Package for the Social Sciences (SPSS 20.0). Descriptive statistics and the Chi-square test were done to determine the significant effects of different explanatory variables on percentage values of parasitism.

\section{Results and Discussion}

\section{Overall prevalence of GI parasitic infections in calves}

Out of the 413 calves examined through fecal examination, 187 were found infected with one or more species of GI parasites indicating an overall prevalence of $45.3 \%$ (Table 1). The identified helminths were the snail-borne trematode, namely, Fasciola sp. (1.0\%), two species of protozoa, namely, Giardia sp. (10.4\%) and Cryptosporidium spp. (7.0\%), two species of nematodes, namely, Toxocara spp. (20.3\%) and Strongyloides spp. (3.9\%) and one cestode Moniezia spp. (1.5\%) (Fig. $2)$. However, mixed infection was found only in case of nematodes (Toxocara spp. and
Strongyloides spp.) with the prevalence of $1.2 \%$.

From this study, it was observed that the prevalence of Toxocara spp. (20.3\%) was the highest whereas, Fasciola sp. (1.0\%) infection was the lowest among the parasitic infections in calves (Table 1). The overall prevalence of GI parasitism was lower than the findings of Paul et al. (2016) and Aktaruzzaman et al. (2013) who reported that $72.65 \%$ and $76.9 \%$ cattle were infected with various helminths at Sylhet and Sirajgonj, respectively in Bangladesh. Similarly, Bhattacharyya and Ahmed (2005) and Singh et al. (2008) recorded $65.2 \%$ and $80.0 \%$ incidence of gastrointestinal helminthes, respectively in cattle in India. The variation between the present and earlier results might be due to the differences among the geographical locations and climatic conditions of the study areas, feeding, management and genetic variation in host resistance as well as a gradual increase in awareness of farmers about routine deworming in study areas. Similar to this study, calves were mostly infected with Toxocara spp. and

Table 1. Overall prevalence of GI parasitic infection in calves

\begin{tabular}{llcc}
\hline Types of Parasites & \multicolumn{1}{c}{ Name of Parasites } & $\begin{array}{c}\text { No. Infected } \\
(\mathrm{N}=413)\end{array}$ & Prevalence (\%) \\
\cline { 2 - 4 } Nematode & Toxocara spp. & 84 & 20.3 \\
& Strongyloides spp. & 16 & 3.9 \\
& Mixed (Toxocara spp. and Strongyloides spp.) & 5 & 1.2 \\
Trematode & Fasciola sp. & 4 & 1.0 \\
Cestode & Moniezia spp. & 6 & 1.5 \\
\multirow{2}{*}{ Protozoa } & Giardia sp. & 43 & 10.4 \\
& Cryptosporidium spp. & 29 & 7 \\
\hline Overall & & 187 & 45.3 \\
\hline
\end{tabular}




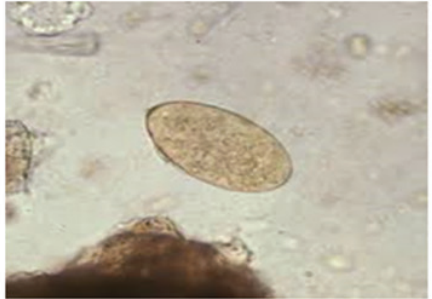

A. Egg of Fasciola sp.

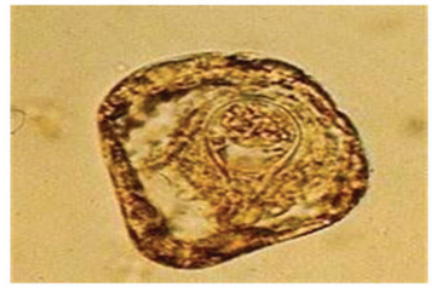

D. Egg of Moniezia sp.

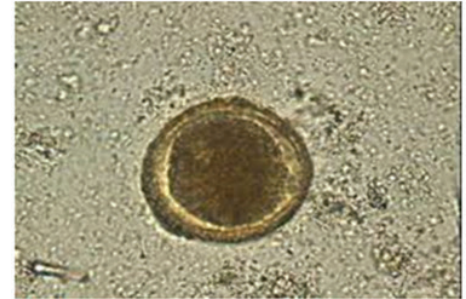

B. Egg of Toxocarasp.

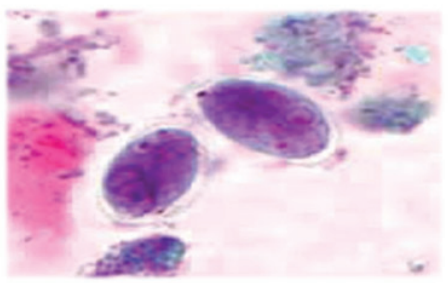

E. Cyst of Giardia sp. (Lugol's Iodine staining)

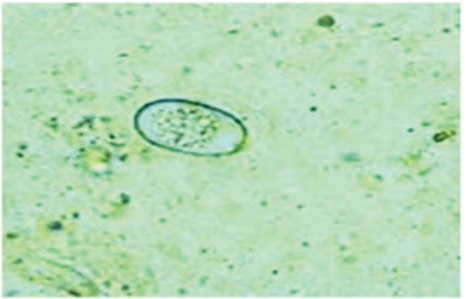

C. Egg of Strongyloides sp.

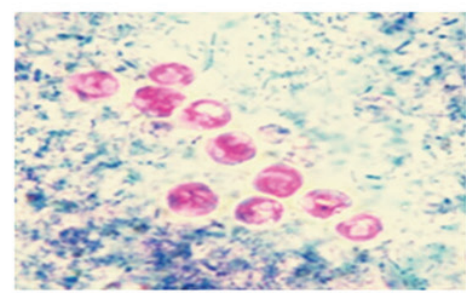

F. Oocyst of Ciyptosporidium sp. (Modified Ziehl-Neelson staining)

Fig. 2. Identified GI parasites in this study.

high prevalence of infection might be related to prenatal infection with 3rd larval stage, and poor hygienic condition during postnatal period (Miller et al., 2013). However, similar types of parasites as reported in this study were detected by different scientists in different areas with variable rate of infections (Ahmed et al., 2015; Islam et al., 2014; Fayer, 2010; Xiao, 2010). In Bangladesh, most of the calves in rural areas are reared in scavenging or semi scavenging system, where they graze on the fields. This type of practice may favor the parasitic infestations in calves.

\section{Diversity of GI parasitic infection according to study location}

The prevalence of different GI parasitic infections in three study districts varied from 44.5 to $46.3 \%$. The lowest parasitic infection (44.5\%) was recorded in Pabna district though infection by different species of parasites in study areas was statistically not significant
(Table 2). The slight difference in the prevalence of GI parasitic infections might be due to variation in geo-climatic conditions of these areas of study.

\section{Prevalence of GI parasitic infections in relation to age}

The prevalence of GI parasitic infections varied significantly ( $p=0.037$ ) among different age groups of calves and the highest infection was recorded in calves of $>3$ to $\leq 6$ months $(54.4 \%)$ and lowest in calves of $\leq 3$ months $(36.6 \%)$ of age (Table 3$)$.

The prevalence of Toxocara spp. infection was the highest in calves of $>3$ to $\leq 6$ months (29.4\%) and the lowest in the calves of $>6$ to $\leq 8$ months $(8.2 \%)$. The protozoan infection by Giardia sp. (16.4\%) and Cryptosporidium spp. $(8.2 \%)$ were the highest in the calves of $>6$ months to $\leq 8$ months. Prevalence of snail-borne trematode infection was found 
Table 2. Diversity of GI parasitism in calves in different study areas

\begin{tabular}{lcccc}
\hline \multirow{2}{*}{ Type of Parasites } & \multicolumn{3}{c}{ Study area } & \\
\cline { 2 - 4 } & $\begin{array}{c}\text { Sirajgonj }(\%) \\
(\mathrm{n}=163)\end{array}$ & $\begin{array}{c}\text { Pabna }(\%) \\
(\mathrm{n}=209)\end{array}$ & $\begin{array}{c}\text { Gazipur }(\%) \\
(\mathrm{n}=41)\end{array}$ & $p$-value \\
\hline Toxocara spp. & $31(19.0)$ & $42(20.1)$ & $11(26.8)$ & 0.54 \\
Strongyloides spp. & $7(4.3)$ & $9(4.3)$ & $0(0.0)$ & 0.40 \\
Mixed (Toxocara spp. and & $4(2.5)$ & $0(0.0)$ & $1(2.4)$ & 0.08 \\
Strongyloides spp.) & $1(0.6)$ & $2(1.0)$ & $1(2.4)$ & 0.57 \\
Fasciola sp. & $3(1.8)$ & $3(1.4)$ & $0(0.0)$ & 0.68 \\
Moniezia spp. & $18(11.0)$ & $20(9.6)$ & $5(12.2)$ & 0.83 \\
Giardia sp. & $11(6.7)$ & $17(8.1)$ & $1(2.4)$ & 0.42 \\
Cryptosporidium spp. & $75(46.0)$ & $93(44.5)$ & $19(46.3)$ & \\
\hline Total & & & & \\
\hline
\end{tabular}

Table 3. Prevalence of GI parasitic infections in calves in relation to Age

\begin{tabular}{|c|c|c|c|c|}
\hline \multirow[b]{2}{*}{ Type of Parasites } & \multicolumn{3}{|c|}{ Age category } & \multirow[b]{2}{*}{$p$-value } \\
\hline & $\begin{array}{l}\leq 3 \text { months }(\%) \\
(\mathrm{n}=172)\end{array}$ & $\begin{array}{c}>3 \text { to } \leq 6 \text { months }(\%) \\
(\mathrm{n}=180)\end{array}$ & $\begin{array}{c}>6 \text { to } \leq 8 \text { months } \\
(\%)(n=61)\end{array}$ & \\
\hline Toxocara spp. & $26(15.1)$ & $53(29.4)$ & $5(8.2)$ & \multirow{8}{*}{0.037} \\
\hline Strongyloides spp. & $7(4.1)$ & $7(3.9)$ & $2(3.3)$ & \\
\hline $\begin{array}{l}\text { Mixed (Toxocara spp. and } \\
\text { Strongyloides spp.) }\end{array}$ & $2(1.2)$ & $3(1.7)$ & $0(0.0)$ & \\
\hline Fasciola sp. & $0(0.0)$ & $1(0.6)$ & $3(4.9)$ & \\
\hline Moniezia spp. & $0(0.0)$ & $5(2.8)$ & $1(1.6)$ & \\
\hline Giardia sp. & $16(9.3)$ & $17(9.4)$ & $10(16.4)$ & \\
\hline Cryptosporidium spp. & $12(7.0)$ & $12(6.7)$ & $5(8.2)$ & \\
\hline Total & $63(36.6)$ & $98(54.4)$ & $26(42.6)$ & \\
\hline
\end{tabular}

to increase with the increase of age and was highest at age of $>6$ to $\leq 8$ months $(4.9 \%)$. Fasciola sp. was not recorded in calves less than 3 months of age. Susceptibility of calves to Moniezia spp. was highest in calves of $>3$ to $\leq 6$ months $(2.8 \%)$ and absent in calves under 3 months (Table 3). This result is inclined with the results by Raza et al. (2010) and Samad et al. (2004) who reported that these parasites are mostly prevalent in young age.
The cause of this high prevalence in young cattle might be due to sudden exposure to grassland containing huge number of eggs of parasites, and possibly due to lack of necessary protective immunity of the calves. Fasciola sp. and Moniezia spp. were not observed in calves under 3 months of age. This might be the consequences of feeding habit of calves and time requirement for completing the life cycle of these parasites. However, Rahman 
and Mondal (1983) found heavy infection of Fasciola sp. in cattle of 2-3 years of age than in the young cattle.

\section{Sex-wise distribution of GI parasites in calves}

In the present study, prevalence of GI parasitic infection was observed significantly $(p=0.029)$ higher in male $(48.4 \%)$ than in female calves $(42.5 \%)$ (Table 4$)$. In males, the highest prevalent parasite was Toxocara spp. (18.8\%) followed by Giardia sp. (12.0\%), Cryptosporidium spp. (9.9\%), Strongyloides spp. (4.7\%), Fasciola sp. (1.6\%), and Moniezia spp. (1.0\%).

In female calves, the highest prevalence was recorded for Toxocara spp. (21.7\%) and lowest for Fasciola sp. (0.5\%) (Table 4). Similar to this finding, higher prevalence was reported in male animals than in females by some other studies in Bangladesh, Pakistan and Ethiopia (Paul et al., 2016; Hailu et al., 2011; Ibrahim et al., 2008). On the other hand, higher rate of parasite infection in female animals than in male was also reported (Das et. al., 2010; Islam and Taimur, 2008). However, Siddiki et al. (2010) observed that both male and female Red Chittagong Cattle breed and crossbred animals were equally susceptible to parasitic infections. The higher percentage of infection in the male cannot be explained exactly, but it might be due to the neglected attitude of the farmers toward the management of male animals since many of the farms target milk production thereby focusing more on the health of females. In addition, higher feed and water intake might make the male individual more susceptible to any infection (Paul et al., 2016).

\section{Variation in GI parasitism according to breed}

In this study, prevalence of parasitic infection was more common in cross breed calves $(48.0 \%)$ than in indigenous calves $(34.5 \%)$. But the difference was not significant ( $p=$ 0.816) (Table 5). In both breeds, the highest prevalence of GI parasitic infection was recorded for Toxocara spp. $(21.6,15.5 \%)$

Table 4. Prevalence of GI parasitic infections in calves of different sexes

\begin{tabular}{|c|c|c|c|}
\hline \multirow[b]{2}{*}{ Type of Parasites } & \multicolumn{2}{|c|}{ Sex category } & \multirow[b]{2}{*}{$p$-value } \\
\hline & $\begin{array}{l}\text { Male }(\%) \\
(n=192)\end{array}$ & $\begin{array}{c}\text { Female }(\%) \\
\mathrm{N}=221\end{array}$ & \\
\hline Toxocara spp. & $36(18.8)$ & $48(21.7)$ & \multirow{8}{*}{0.029} \\
\hline Strongyloides spp. & $9(4.7)$ & $7(3.2)$ & \\
\hline Mixed (Toxocara spp. and Strongyloides spp.) & $1(0.5)$ & $4(1.8)$ & \\
\hline Fasciola sp. & $3(1.6)$ & $1(0.5)$ & \\
\hline Moniezia spp. & $2(1.0)$ & $4(1.8)$ & \\
\hline Giardia sp. & $23(12.0)$ & $20(9.0)$ & \\
\hline Cryptosporidium spp. & $19(9.9)$ & $10(4.5)$ & \\
\hline Total & $93(48.4)$ & $94(42.5)$ & \\
\hline
\end{tabular}


Table 5. Prevalence of GI parasitism in calves according to breed

\begin{tabular}{lccc}
\hline \multirow{2}{*}{ Type of Parasites } & \multicolumn{2}{c}{ Breed } & \\
\cline { 2 - 3 } & $\begin{array}{c}\text { Indigenous }(\%) \\
(\mathrm{n}=84)\end{array}$ & $\begin{array}{c}\text { Crossbred }(\%) \\
(\mathrm{n}=329)\end{array}$ & \\
\hline Toxocara spp. & $13(15.5)$ & $71(21.6)$ \\
Strongyloides spp. & $3(3.6)$ & $13(4.0)$ & \\
Mixed (Toxocara spp. and Strongyloides spp.) & $0(0.0)$ & $5(1.5)$ & \\
Fasciola sp. & $1(1.2)$ & $3(0.9)$ & 0.816 \\
Moniezia spp. & $1(1.2)$ & $5(1.5)$ & \\
Giardia sp. & $5(6.0)$ & $38(11.6)$ & \\
Cryptosporidium spp. & $6(7.1)$ & $23(7.0)$ & \\
Total & $29(34.5)$ & $158(48.0)$ &
\end{tabular}

and the lowest for Fasciola sp. (0.9\%, 1.2\%). Similar findings had been described by Gadre (2007) who reported that the infection rates with GI parasitic infections in cross-bred cattle were relatively higher than in local dairy animals. This study revealed that the infection rate with Toxocara spp. was comparatively higher in cross-breed $(21.6 \%)$ than in the indigenous calves $(15.5 \%)$ which are almost similar to the earlier report by Roy (2010).

Holstein Frisian and Jersey are usually adapted in countries having relatively low temperature with minimal chances of parasitic exposure. The parasitic ecology and reproduction are closely related to an optimal environmental condition, which is not normally common in these countries. But, Bangladesh is a tropical country with hot-humid environment which is favorable for parasite reproduction. For this reason, crossbred animals in Bangladesh become readily infected by parasites and different predisposing factors including managing of these animals in parasitic load environment further worsen the condition.

\section{Effect of health status on GI parasitic infections}

Health status of calves had significant $(p=0.004)$ effect on the occurrence of GI parasitism and infections were higher in poor health conditioned calves $(76.5 \%)$ than that of normal conditioned (39.1\%). In calves with poor health, the highest prevalence was recorded in case of Toxocara spp. (44.1\%) followed by Giardia sp. (11.8\%), Strongyloides spp. (7.4\%), Fasciola sp. (4.4\%), Cryptosporidium spp. (4.4\%), and Moniezia spp. (1.5\%). In healthy calves, the highest prevalence was found for Toxocara spp. (15.7\%) and the lowest for Fasciola sp. $(0.3 \%)$ (Table 6).

This finding coincides with the result reported by Ilyas et al. (2016) and Alim et al. (2012). Malnourished animals are more susceptible to any infection as they are immune compromised. It appears that malnutrition in animals increases their susceptibility to the parasitic infection (Biswas et al., 2014). It may also happen due to the fact that the poor 
10 Prevalence and Factors Affecting the Parasitic Infections in Calves at Selected Areas of Bangladesh

Table 6. Health status related prevalence of GI parasitism in calves

\begin{tabular}{lccc}
\hline \multirow{2}{*}{ Type of Parasites } & \multicolumn{2}{c}{ Health status } & \multirow{2}{*}{$p$-value } \\
\cline { 2 - 3 } & Normal $(\%)(\mathrm{n}=345)$ & Poor $(\%)(\mathrm{n}=68)$ & \\
\hline Toxocara spp. & $54(15.7)$ & $5(44.1)$ & \\
Strongyloides spp. & $11(3.2)$ & $2(2.9)$ & \\
Mixed (Toxocara spp. and Strongyloides spp.) & $3(0.9)$ & $3(4.4)$ & 0.004 \\
Fasciola sp. & $1(0.3)$ & $1(1.5)$ & \\
Moniezia spp. & $5(1.4)$ & $8(11.8)$ & \\
Giardia sp. & $35(10.1)$ & $3(4.4)$ & \\
Cryptosporidium spp. & $26(7.5)$ & $52(76.5)$ & \\
Total & $135(39.1)$ & &
\end{tabular}

and weak animals, as a result of any other causes, are not able to resist the challenge of parasitic infection and become easily infected.

\section{Relationship between fecal consistency and GI parasitic infections in calves}

Calves with loose feces had more parasitic infection $(56.5 \%)$ than the calves with formed (21.7\%) and soft (18.7\%) feces, however the difference was not significant (Table 7). Among the parasites, Toxocara spp. was more common in calves with each type of feces $($ loose $=21.7 \%$, formed $=18.7 \%$ and soft $=21.0 \%$ ) whereas Fasciola sp. and Moniezia spp. were found in calves with soft $(0.6 \%$ and $2.9 \%$, respectively) and loose feces ( $4.8 \%$ and $1.6 \%$, respectively). Loose feces is a common clinical finding in many parasitic as well as bacterial and viral diseases that make animal immunecompromised and vulnerable. For this reason, calves with loose feces might have more parasitic infection than others.

Table 7. Prevalence of GI parasitic infections in calves based on fecal consistency

\begin{tabular}{|c|c|c|c|c|}
\hline \multirow[b]{2}{*}{ Type of Parasites } & \multicolumn{3}{|c|}{ Fecal Consistency } & \multirow[b]{2}{*}{$p$-value } \\
\hline & $\begin{array}{l}\text { Formed }(\%) \\
\quad(n=180)\end{array}$ & $\begin{array}{l}\text { Soft }(\%) \\
(\mathrm{n}=171)\end{array}$ & $\begin{array}{l}\text { Loose }(\%) \\
(n=62)\end{array}$ & \\
\hline Toxocara spp. & $39(21.7)$ & $32(18.7)$ & $13(21.0)$ & \multirow{8}{*}{0.424} \\
\hline Strongyloides spp. & $7(3.9)$ & $7(4.1)$ & $2(3.2)$ & \\
\hline $\begin{array}{l}\text { Mixed (Toxocara spp. and } \\
\text { Strongyloides spp.) }\end{array}$ & $2(1.1)$ & $2(1.2)$ & $1(1.6)$ & \\
\hline Fasciola sp. & $0(0.0)$ & $1(0.6)$ & $3(4.8)$ & \\
\hline Moniezia spp. & $0(0.0)$ & $5(2.9)$ & $1(1.6)$ & \\
\hline Giardia sp. & $16(8.9)$ & $17(9.9)$ & $10(16.1)$ & \\
\hline Cryptosporidium spp. & $12(6.7)$ & $12(7.0)$ & $5(8.1)$ & \\
\hline Total & $76(42.2)$ & $76(44.4)$ & $35(56.5)$ & \\
\hline
\end{tabular}




\section{Conclusions}

GI parasitic infections are common among calves in Pabna, Sirajgonj and Gazipur districts. The highest prevalence was found for Toxocara spp. and the lowest for Fasciola sp. It was also found that age, sex and health status had significant effects on the prevalence of GI parasitism in calves. Parasitic diseases pose great effects on health and production of animals. Economic losses due to mortality and morbidity in calves per year in Bangladesh may be determined by further studies. More extensive research including molecular epidemiology may be conducted to develop cost effective sustainable control strategies against GI parasitism.

\section{Acknowledgements}

The authors acknowledge the financial support from the Research Management Wing (RMW) of Bangabandhu Sheikh Mujibur Rahaman Agricultural University (BSMRAU) and University Grants Commission of Bangladesh. We are grateful to Professor Dr. Abu Sadeque Md. Selim, Department of Animal Science \& Nutrition, BSMRAU for making the laboratory space and equipment available for this study.

\section{References}

Afazuddin, M. 1985. General incidence and therapeutic measures of parasitic diseases in cattle of Savar Military Dairy Farm. MSc Thesis, Department of Medicine, Bangladesh Agricultural University, Mymensingh.

Ahmed, R., P. K. Biswas, M. Barua, M. A. Alim, K. Islam and M. Z. Islam. 2015. Prevalence of gastrointestinal parasitism of cattle in Banskhali upazilla, Chittagong, Bangladesh. J. Adv. Vet. Anim. Res. 2(4): 484-488.

Akanda, M. R., M. M. I. Hasan, S. A. Belal and A. C. Roy. 2014. A survey on prevalence of gastrointestinal parasitic infection in cattle of Sylhet division in Bangladesh. American J. Phyto. Clin. Therap.2: 855-860.

Aktaruzzaman, M., S. A. Rony, M. A. Islam, M. G. Yasin and A. K. M. A. Rahman. 2013. Concurrent infection and seasonal distribution of gastrointestinal parasites in cross-bred cattle of Sirajganj district in Bangladesh. Vet. World. 6(10): 720-724.

Alim, M. A., S. Das, K. Roy, S. Sikder, Mohiuddin, M. Masuduzzaman and M. A. Hossain. 2012. Prevalence of gastrointestinal parasites in cattle of Chittagong division, Bangladesh. Wayamba J. Animal Sci. 4: 1-8.

Bhattacharyya, D. K. and K. Ahmed. 2005. Prevalence of helminthic infection in cattle and buffaloes. Indian Vet. J. 82: 900-901.

Biswas, H., A. R. Dey, N. Begum and P. M. Das. 2014. Epidemiological aspects of gastrointestinal parasites in buffaloes in Bhola, Bangladesh. Indian J Anim Sci. 84: 245-250.

Charlier, J., F. V. Velde, M. Van Der Voort, J. V. Meensel, L. Lauwers, V. Cauberghe, J. Vercruysse and E. Claerebout. 2015. Econohealth: Placing helminth infections of livestock in an economic and social context. Vet. Parasitol. 212: 62-67.

Chavhan, P. B., L. A. Khan, P. A. Raut, D. K. Maske, S. Rahman, K. S. Podchalwar, and M. F. Siddiqui. 2008. Prevalence of nematode parasites of ruminants at Nagpur. Vet. World. 1: 140.

Das, S., A. K. F. H. Bhuiyan, N. Begum, M. A. Habib and T. Arefin. 2010. Fertility and 
12 Prevalence and Factors Affecting the Parasitic Infections in Calves at Selected Areas of Bangladesh

parasitic infestation of Red Chittagong cattle. Bangladesh Vet. 27(2): 74-81.

Dryden, M. W., P. A. Payne, R. Ridley and V. Smith. 20115. Comparison of common fecal flotation techniques for the recovery of parasite eggs and oocysts. Vet. Therapeut. 6 (1): 15-28.

Fayer, R., M. Santin and D. Macarisin. 2010. Cryptosporidium ubiquitum n. $\mathrm{sp}$. in animals and humans. Vet. Parasitol. 172: 23-32.

Gadre, S.K. and H. Harada. 2007. Surface water pollution in three urban territories of Nepal, India, and Bangladesh. Environ. Manage. 28: 483-496.

Gunathilaka, N., D.Niroshana, D. Amarasinghe and L. Udayanga. 2018. Prevalence of gastrointestinal parasitic infections and assessment of deworming program among cattle and buffaloes in gampaha district, Sri Lanka. BioMed Res. Int. https://doi. org/10.1155/2018/3048373.

Hailu, D., A. Cherenet, Y. Moti and T. Tadele. 2011. Gastrointestinal helminth infections in small-scale dairy cattle farms of jimma town, Ethiopia. Ethiop. J. Sci. Technol. 2(1): $31-37$.

Hendawy, S. H. M. 2018. Immunity to gastrointestinal nematodes in ruminants: effector cell mechanisms and cytokines. $J$. Parasit. Dis. 42: 471-482

Hendrix, C. M. 2002. Laboratory procedures for veterinary technicians. Mosby, Philadelphia.

Hossain, M. J., M. Amin, M. Mostofa, M. Sharif and S. M. A. Khalid. 2004. Efficacy of levanid against natural gastrointestinal nematodiasis and paramphistomiasis in sheep. Bangladesh Vet. J. 21 (2): 70-73.

Ibrahim, M. M., M. A. A. Ghamdi and M. S. A. Gahmdi. 2008. Helminths Community of Veterinary Importance of Livestock in Relation to Some Ecological and Biological Factors. Turkiye Parazitol Derg. 32: 42-47.

Ilyas, N., M. M. Hossain, M. J. U. Bhuyan and M. M. H. Khan. 2016. Prevalence of Gastrointestinal Nematodes Infection of Cattle in Bangladesh. American J. Phyto. Clin. Therap. 4(3): 091-097.

Islam, M. R., M. G. Yasin, M. A. Al Noman, N. Begum, M. M. H. Mondal. 2014. Prevalence of gastrointestinal parasites in cattle at Vangura upazila in Pabna district of Bangladesh. Int. J. Nat. Soc. Sci. 1: 45-52.

Islam, K. B. M. S. and M. J. F. A. Taimur. 2008. Helminthic and protozoan internal parasitic infections in free ranging small ruminants of Bangladesh. Slov. Vet. Res. 45: 67-72.

Jabber, M. and D. A. G. Green. 1983. The status and potential of livestock within the context of agricultural development policy in Bangladesh. The University of Wales. Aberystwyth, United Kingdom. 113 P.

Miller, R. S., M. L. Farnsworth and J. L. Malmberg. 2013. Diseases at the livestockwildlife interface: status, challenges, and opportunities in the United States. Prev. Vet. Med.110: 119-132.

Paul, A., P. C. Baishnab, H. Kobir, S. Akhter, T. J. Chowdhury, B. Jha and M. M. Rahman. 2016. Status of internal parasitism of cattle at Sylhet Government Dairy Farm, Bangladesh. Int J Nat Sci. 6(2): 54-34.

Pinilla, J. C., P. Florez, M. T. Sierra, E. Morales, R. Sierra, M. C. Vasquez and D. Ortiz. 2018. Point prevalence of gastrointestinal parasites in double purpose cattle of Rio de Oro and Aguachica municipalities, Cesar state, Colombia. Vet Parasitol Reg Stud Reports. 12: 26-30.

Pinilla León, J. C., N. U. Delgado and A. A. Florez. 2019. Prevalence of gastrointestinal parasites in cattle and sheep in three municipalities in 
the Colombian Northeastern Mountain. Vet. World. 12(1): 48-54.

Rahman, M. F. and Z. Ahmed. 1991. Final report of "Pilot project for the control of parasitic disease of animals in Bangladesh", Bangladesh Livestock Research Institute, Dhaka.

Rahman, M. H. and M. M. H. Mondol. 1983. Helminth parasites of cattle (Bosindicus) in Bangladesh. Indian J. Parasitol. 7(2): 173174.

Raza, A. M., S. Murtaza, H. A. Bachaya, A. Qayyum and M. A. Zaman. 2010. Point prevalence of Toxocara vitulorum in Large Ruminants Slaughtered at Multan Abattoir. Pak Vet J. 30: 242-244.

Roy, M. M. Alam, A. K. M. A. Rahman, M. Shahiduzzaman, M. S. Parvez and E. H. Chowdhury. 2010. Prevalence of cryptosporidiosis in crossbred calves in two selected areas of Bangladesh. Bangladesh J. Vet. Med.12: 185-190.

Samad, M. A., K. M. M. Hossain, M. A. Islam and S. Saha. 2004. Concurrent infection of gastro-intestinal parasites and bacteria associated with diarrhea in calves. Bang. J. Vet. Med. 2(1): 49-54.

Sardar, S. A., M. A. Ehsan, A. K. M. M. Anower, M. M. Rahman and M. A. Islam. 2006.
Incidence of liver flukes and gastrointestinal parasites in cattle. Bang. J. Vet. Med. 4 (1): 39-42.

Siddiki, A. Z., M.B. Uddin, M. B. Hasan, M. F. Hossain, M. M. Rahman, B. C. Das, M. S. Sarkerand M. A. Hossain. 2010. Coproscopic and haematological approaches to determine the prevalence of helminthiasis and protozoan diseases of Red Chittagong Cattle (RCC) breed in Bangladesh. Pak. Vet. J. 30(1): 1-6.

Singh, A., A. K. Gangwar, N. K. Shinde and S. Srivastava. 2008. Gastrointestinal parasitism in bovines of Faizabad. J. Vet. Parasitol. 22(1): 31-33.

Tahvildar-Biderouni, F. and N. Salehi. 2014. Detection of Cryptosporidium infection by modified ziehl-neelsen and PCR methods in children with diarrheal samples in pediatric hospitals in Tehran. Gastroenterol Hepatol Bed Bench. 7(2): 125-30.

Taylor, M. A., R. L. Coop, and R. L. Wall. 2016. Veterinary Parasitology: 4th ed. Blackwell publishing, Oxford.

Thrusfield, M. 2007. Veterinary epidemiology. $3^{\text {rd }}$ Edition, Blackwell science, Oxford, UK.

Xiao, L. 2010. Molecular epidemiology of cryptosporidiosis: an update. Exp Parasitol. 124(1): 80-89. 
